07

\title{
Циркулярно поляризованная электролюминесценция спиновых светодиодов с ферромагнитным инжектором (In,Fe)Sb
}

\author{
(C) М.В. Ведь, М.В. Дорохин, В.П. Лесников, А.В. Кудрин, П.Б. Дёмина, А.В. Здоровейщев, \\ Д.А. Павлов, Ю.В. УСов, В.Е. Милин, Ю.А. Данилов
}

Нижегородский государственный университет им. Н.И. Лобачевского, Нижний Новгород, Россия

E-mail: mikhail28ved@gmail.com

Поступило в Редакцию 27 марта 2020г.

В окончательной редакции 10 апреля 2020г.

Принято к публикации 10 апреля 2020г.

\begin{abstract}
Исследована возможность использования разбавленного магнитного полупроводника ( $\mathrm{In}, \mathrm{Fe}) \mathrm{Sb}$ в качестве функционального слоя для применения в спинтронике, а именно в качестве ферромагнитного инжектора в спиновом светоизлучающем диоде. Изучены люминесцентные характеристики, а также температурная зависимость степени циркулярной поляризации электролюминесценции спинового светодиода с инжектором $(\mathrm{In}, \mathrm{Fe}) \mathrm{Sb}$.
\end{abstract}

Ключевые слова: разбавленные магнитные полупроводники, диодные структуры, гетеронаноструктуры $\mathrm{A}^{3} \mathrm{~B}^{5}$, спиновая инжекция.

DOI: 10.21883/PJTF.2020.14.49660.18313

В настоящее время область науки, связанная с разработкой и изучением спиновых светоизлучающих диодов (ССИД), являющихся источниками циркулярно поляризованной люминесценции, получила значительное развитие. В основном в качестве инжекторов спин-поляризованных носителей в ССИД используются многослойные структуры на основе ферромагнитных металлов [1]. В качестве альтернативы предлагается использование разбавленных магнитных полупроводников (РМП), которые являются перспективными материалами для спиновых инжекторов. Разбавленные магнитные полупроводники представляют собой немагнитные материалы, легированные магнитными примесями (переходными $3 d$-металлами) и, следовательно, сочетающие магнитные и полупроводниковые свойства [2]. Основное преимущество РМП состоит в совместимости с современными полупроводниковыми технологиями [3]. С другой стороны, недостатком большинства разбавленных магнитных полупроводников, который в настоящее время существенно ограничивает их применение, является низкая температура Кюри. На данный момент наиболее изученный среди разбавленных магнитных полупроводников материал (Ga,Mn)As сохраняет ферромагнитные свойства только до $200 \mathrm{~K}$, а это значит, что устройства спинтроники на основе указанного материала будут функционировать только до $200 \mathrm{~K}$ [4]. Поэтому задача повышения температуры Кюри для РМП является одной из наиболее актуальных в технологии спинтроники. В последние годы активно проводились исследования, посвященные сильному легированию материалов $\mathrm{A}^{3} \mathrm{~B}^{5}$ атомами $\mathrm{Fe}$ для получения разбавленных магнитных полупроводников $\left(\mathrm{A}^{3}, \mathrm{Fe}\right) \mathrm{B}^{5}$. В [5] с использованием метода импульсного лазерного осаждения были получены тонкие слои разбавленного магнитного полупроводника
(In,Fe)Sb c содержанием Fe 13\%. Впервые было показано, что температура Кюри такого материала превышает 300 K. В [6] также были получены ферромагнитные слои $(\mathrm{In}, \mathrm{Fe}) \mathrm{Sb}$ (содержание $\mathrm{Fe} 16 \%$ ) с температурой Кюри выше $300 \mathrm{~K} \mathrm{с} \mathrm{использованием} \mathrm{молекулярно-лучевой} \mathrm{эпи-}$ таксии.

Ранее в нашей работе [7] было показано, что слои $(\mathrm{In}, \mathrm{Fe}) \mathrm{Sb}$ могут использоваться в структуре спинового светодиода в качестве функционального контактного слоя при нанесении на поверхность полупроводниковых структур, сформированных на GaAs p-типа. На основании вольт-амперных характеристик и зонных диаграмм было обнаружено, что механизмы инжекции в таких структурах будут близки к таковым в диодах Шоттки [7].

В настоящей работе сообщается о создании и исследовании источника циркулярно поляризованного излучения - спинового светоизлучающего диода с ферромагнитным инжектором в виде слоя (In,Fe)Sb.

Формирование исследуемого образца осуществлялось в три этапа. На первом этапе полупроводниковая часть структуры выращивалась методом эпитаксии из металлоорганических соединений (МОС-гидридная эпитаксия) при атмосферном давлении. На подложке $p$-GaAs последовательно формировались следующие слои: буферный слой $p$-GaAs, квантовая яма $\operatorname{In}_{x} \mathrm{Ga}_{1-x}$ As (толщина $10 \mathrm{~nm}, x=0.22)$ и спейсерный слой $i$-GaAs толщиной $20 \mathrm{~nm}$. Ранее было показано, что свойства гетероперехода ( $\mathrm{In}, \mathrm{Fe}) \mathrm{Sb} / \mathrm{GaAs}$ сильно влияют на электролюминесценцию спиновых светоизлучающих диодов. Осаждение защитного слоя диэлектрика $\mathrm{MgO}$ между $\mathrm{GaAs}$ и ( $\mathrm{In}, \mathrm{Fe}) \mathrm{Sb}$ позволяет улучшить качество гетероперехода [8]. Исходя из этого в настоящей работе на втором этапе также наносился промежуточный защитный слой $\mathrm{MgO}$ толщиной $1 \mathrm{~nm}$ методом электронно-лучевого 


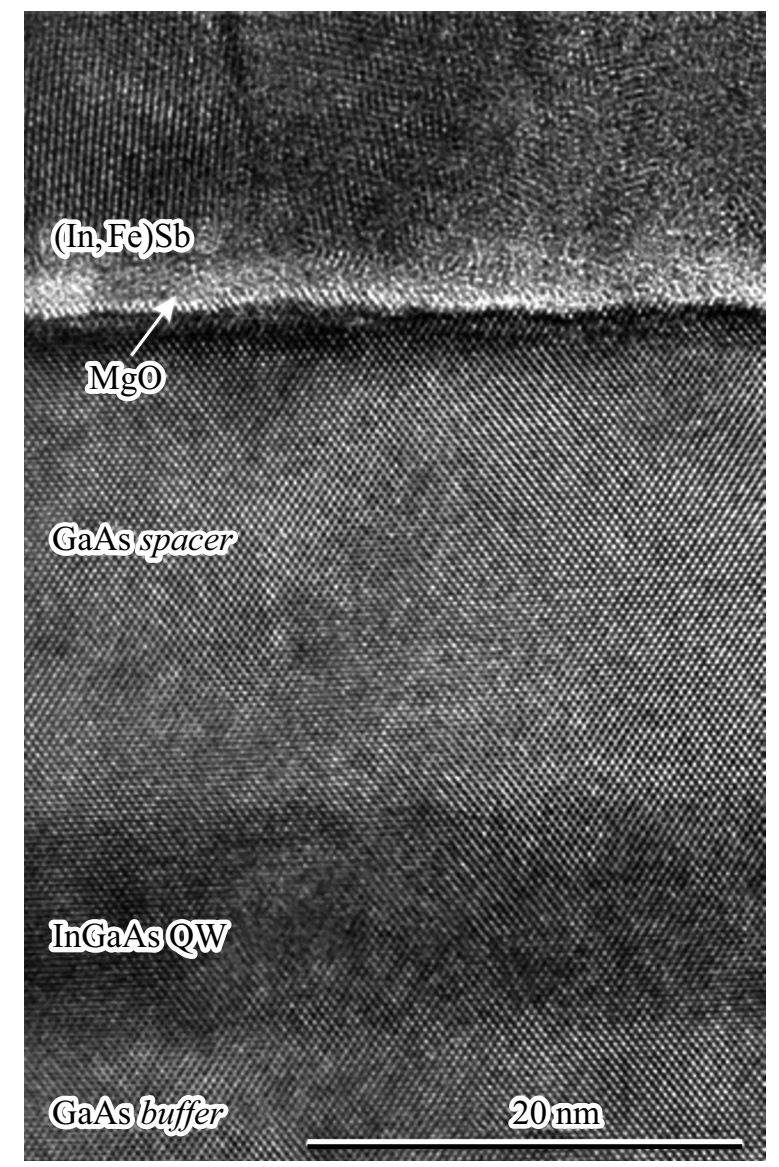

Рис. 1. ВРПЭМ-изображение структуры ССИД для области, включающей квантовую яму, спейсерный слой, слой $\mathrm{MgO}$ и часть слоя $(\mathrm{In}, \mathrm{Fe}) \mathrm{Sb}$.

испарения. На третьем этапе методом импульсного лазерного осаждения в вакууме наносился слой ( $\mathrm{In}, \mathrm{Fe}) \mathrm{Sb}$. Содержание $\mathrm{Fe}$ задавалось технологическим параметром $Y_{\mathrm{Fe}}=t_{\mathrm{Fe}} /\left(t_{\mathrm{Fe}}+t_{\mathrm{InSb}}+t_{\mathrm{Sb}}\right)=0.25$, где $t_{\mathrm{Fe}}, t_{\mathrm{InSb}}$ и $t_{\mathrm{Sb}}-$ времена абляции $\mathrm{Fe}, \mathrm{InSb}$ и дополнительных мишеней $\mathrm{Sb}$ соответственно. Следует отметить, что слои ( $\mathrm{In}, \mathrm{Fe}) \mathrm{Sb}$, изученные в настоящей работе, аналогичны слоям, исследованным в [5].

Затем для создания диодной структуры на поверхность наносился Аu-контакт и формировались мезаструктуры диаметром $500 \mu \mathrm{m}$, также формировался омический In-контакт к подложке методом искрового вжигания.

Структурные свойства образца были исследованы с помощью просвечивающего электронного микроскопа Jeol JEM-2100F. Распределение составляющих элементов было получено методом энергодисперсионной рентгеновской спектроскопии (ЭДС) в процессе микроскопических исследований. Для изучения электролюминесценции (ЭЛ) к образцу прикладывалось прямое смещение (отрицательный потенциал на Аu-контакте относительно подложки). Электролюминесценция регистрировалась со стороны подложки.
При введении структуры в магнитное поле, направленное перпендикулярно поверхности, электролюминесценция становится частично циркулярно поляризованной. Для измерения магнитополевой зависимости циркулярной поляризации использовалась стандартная схема, а степень циркулярной поляризации электролюминесценции рассчитывалась по формуле [2]:

$$
P_{\mathrm{EL}}=\left(I_{1}-I_{2}\right) /\left(I_{1}+I_{2}\right) \cdot 100 \%,
$$

где $P_{\mathrm{EL}}-$ степень циркулярной поляризации электролюминесценции, $I_{1}$ и $I_{2}$ - интенсивности компонент электролюминесценции, поляризованных по левому и правому кругу соответственно.

На рис. 1 показано электронно-микроскопическое изображение, полученное методом высокоразрешающей просвечивающей электронной микроскопии (ВРПЭМ), поперечного сечения исследованной диодной структуры для области, включающей в себя квантовую яму $\mathrm{In}_{x} \mathrm{Ga}_{1-x} \mathrm{As}$, спейсерный слой, слой $\mathrm{MgO}$ и часть слоя $(\mathrm{In}, \mathrm{Fe}) \mathrm{Sb}$.

Изображение демонстрирует высокое кристаллическое качество буферного слоя $\mathrm{GaAs}$, области квантовой

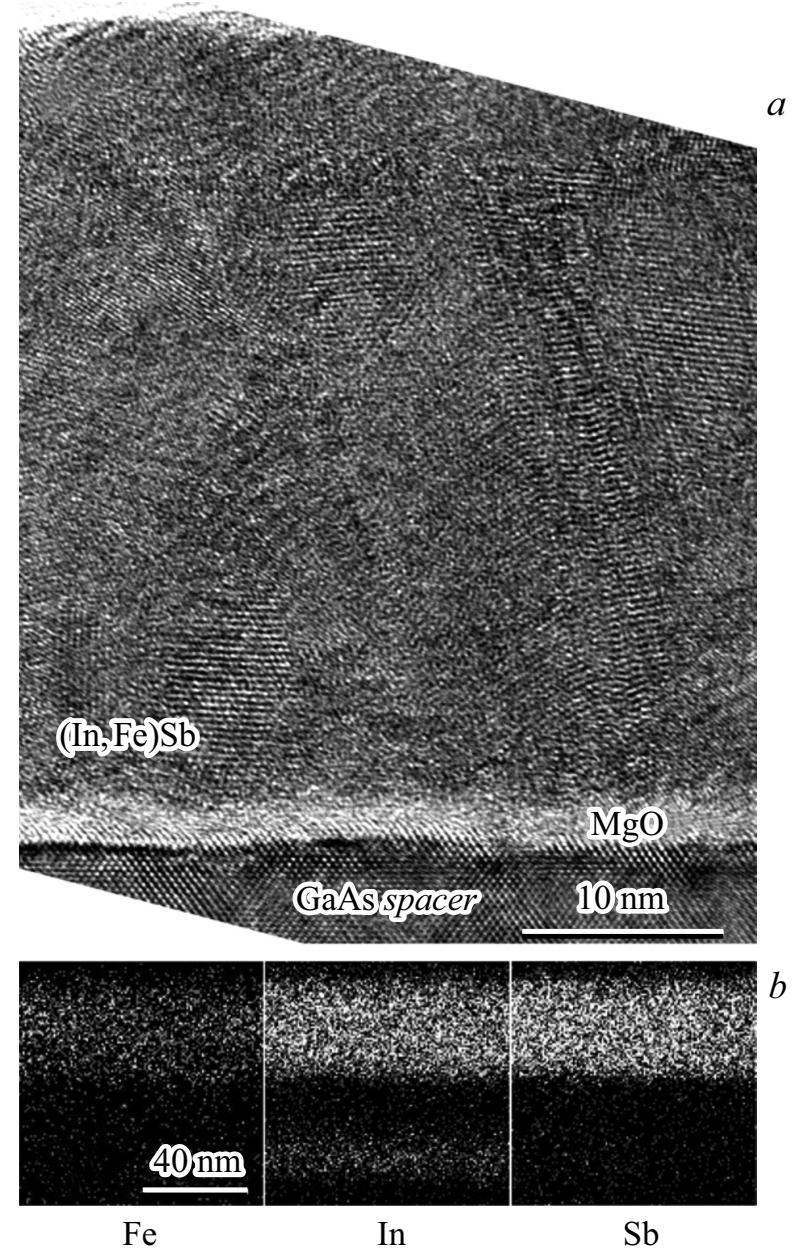

Рис. 2. $a-$ ВРПЭМ-изображение слоя (In,Fe)Sb ССИД, $b-$ карта распределения атомов $\mathrm{Fe}$, In и $\mathrm{Sb}$ в слое ( $\mathrm{In}, \mathrm{Fe}) \mathrm{Sb}$, полученная с помощью ЭДС. 


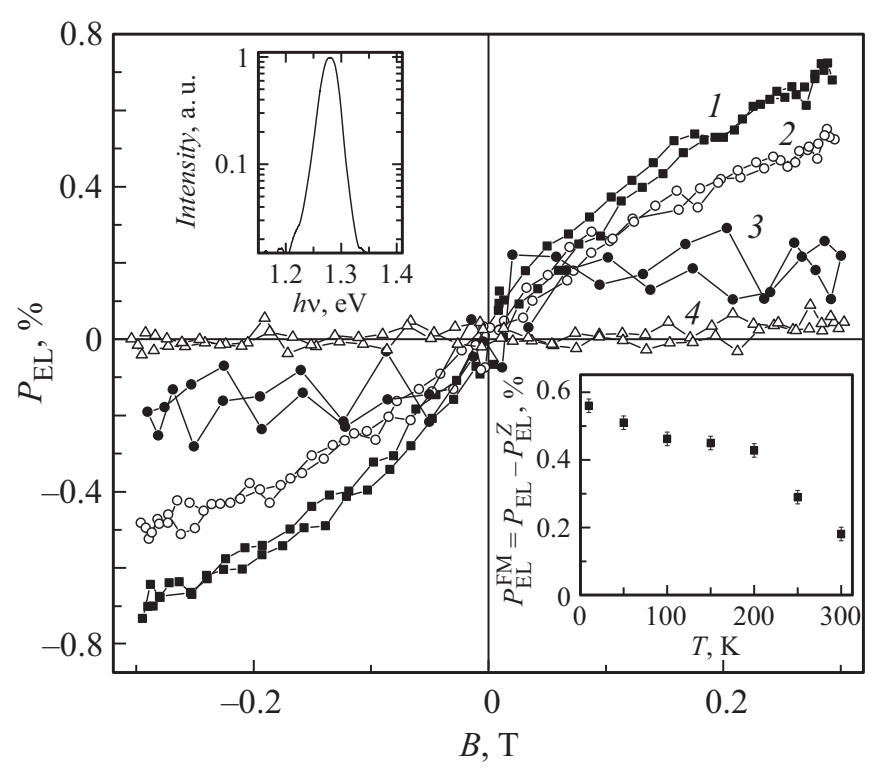

Рис. 3. Зависимости степени циркулярной поляризации $P_{\mathrm{EL}}$ исследуемого образца от магнитного поля, измеренные при различных температурах $(T, \mathrm{~K}: 1-10,2-100,3-300)$, а также аналогичная зависимость для контрольного образца при $10 \mathrm{~K}$ (4); ток через структуры $10 \mathrm{~mA}$. На верхней вставке спектр ЭЛ исследуемой структуры (температура измерений $77 \mathrm{~K}$, ток $10 \mathrm{~mA})$. На нижней вставке - зависимость $P_{\mathrm{EL}}^{\mathrm{FM}}(T)$.

ямы InGaAs и спейсерного слоя GaAs. Толщины квантовой ямы и спейсерного слоя составляют 10 и $23 \mathrm{~nm}$ соответственно, что хорошо согласуется с технологически заданными значениями. Толщина слоя $\mathrm{MgO}$ составляет около $1 \mathrm{~nm}$, а сам слой $\mathrm{MgO}$ является поликристаллическим. Рис. 2, a показывает ВРПЭМ-изображение слоя $(\mathrm{In}, \mathrm{Fe}) \mathrm{Sb}$. Исследования ВРПЭМ указывают на то, что слой $(\mathrm{In}, \mathrm{Fe}) \mathrm{Sb}$ является поликристаллическим (рис. 1 и 2,a). Также на рис. 2,b представлена карта распределения атомов $\mathrm{Fe}$, In и $\mathrm{Sb}$ в слое ( $\mathrm{In}, \mathrm{Fe}) \mathrm{Sb}$, полученная с помощью ЭДС-анализа. Полученные данные свидетельствуют о достаточно равномерном распределении элементов в слое ( $\mathrm{In}, \mathrm{Fe}) \mathrm{Sb}$ без наличия ярко выраженных областей с повышенным содержанием Fe. Исследования ЭДС показывают, что среднее содержание $\mathrm{Fe}$ в слое $(\mathrm{In}, \mathrm{Fe}) \mathrm{Sb}$ составляет около $13 \pm 4$ at.\%. Как было показано нами ранее для гетероструктур ( In, $\mathrm{Fe}) \mathrm{Sb} / \mathrm{GaAs}$, слой (In,Fe)Sb с аналогичными технологическими параметрами является однофазным разбавленным магнитным полупроводником [9]. На основании полученных данных можно сделать вывод, что слой $(\mathrm{In}, \mathrm{Fe}) \mathrm{Sb}$ в структуре светодиода представляет собой поликристаллический РМП.

Спектр электролюминесценции исследуемой структуры, измеренный при температуре $77 \mathrm{~K}$ и токе $10 \mathrm{~mA}$, показан на верхней вставке к рис. 3. В спектре наблюдается доминирующий пик при энергии $1.28 \mathrm{eV}$, соответствующий излучательному переходу в квантовой яме InGaAs c заданным содержанием In. На рис. 3 приведены зависимости степени циркулярной поляризации ЭЛ от магнитного поля, измеренные в диапазоне температур от 10 до $300 \mathrm{~K}$.

Как видно из рис. 3, $P_{\mathrm{EL}}(B)$ является функцией, которая нелинейно зависит от магнитного поля. Максимальная степень циркулярной поляризации, связанная с насыщением намагниченности, составляет $\sim 0.7 \%$ и наблюдается при температуре $10 \mathrm{~K}$. Очевидно, что такой тип зависимости $P_{\mathrm{EL}}(B)$ связан с магнитными свойствами (In, $\mathrm{Fe}) \mathrm{Sb}$, а относительно высокое значение степени поляризации обусловлено инжекцией спинполяризованных электронов из ферромагнитного слоя $(\mathrm{In}, \mathrm{Fe}) \mathrm{Sb}$. Для контрольной структуры без ферромагнитного инжектора ( In, $\mathrm{Fe}$ ) Sb (Al-контакт наносился непосредственно на спейсерный слой GaAs) значение $P_{\mathrm{EL}}$ является линейной функцией магнитного поля (рис. 3, кривая 4), а значение степени циркулярной поляризации не превышает $0.05 \%$. С ростом температуры интенсивность ЭЛ монотонно уменьшается. Также повышение температуры приводит к уменьшению степени циркулярной поляризации исследованных структур. На нижней вставке к рис. 3 приведена температурная зависимость ферромагнитной компоненты степени циркулярной поляризации $P_{\mathrm{EL}}^{\mathrm{FM}}$ (за вычетом поляризации, связанной с зеемановским расщеплением уровней в квантовой яме $\left.[10]: P_{\mathrm{EL}}^{\mathrm{FM}}=P_{\mathrm{EL}}-P_{\mathrm{EL}}^{Z}\right)$. Следует отметить, что в аналогичном образце без слоя $\mathrm{MgO}$ электролюминесценция не наблюдалась в диапазоне токов диода 1-200 mA. Мы предполагаем, что $\mathrm{MgO}$ является защитным слоем, который предотвращает негативное влияние ( $\mathrm{In}, \mathrm{Fe}) \mathrm{Sb}$ на люминесцентные характеристики структур и необходим для нормального функционирования спинового инжектора [8].

Таким образом, был сформирован и исследован спиновый светодиод на основе гетероструктуры $\mathrm{GaAs} / \mathrm{InGaAs}$ с ферромагнитным инжектором в виде разбавленного магнитного полупроводника (In,Fe)Sb, а также разработаны методы повышения интенсивности электролюминесценции путем модификации границы раздела ферромагнетик/полупроводник. Получена спиновая инжекция электронов из разбавленного магнитного полупроводника ( $\mathrm{In}, \mathrm{Fe}) \mathrm{Sb}$ в полупроводниковую структуру на основе $\mathrm{GaAs}$, которая обусловливает циркулярно поляризованное излучение квантовой ямы. Были измерены зависимости степени циркулярной поляризации $P_{\mathrm{EL}}$ от магнитного поля в интервале температур от 10 до $300 \mathrm{~K}$. Максимальное значение $P_{\text {EL }}$ было получено при температуре $10 \mathrm{~K}$ и составило $0.7 \%$.

\section{Финансирование работы}

Работа выполнена при поддержке Российского научного фонда, проект № 18-79-10088 (выращивание образцов и проведение микроскопических исследований), а также Российского фонда фундаментальных исследований, проект № 18-37-00358 (измерения циркулярной поляризации). 


\section{Конфликт интересов}

Авторы заявляют, что у них нет конфликта интересов.

\section{Список литературы}

[1] Liang S.H., Zhang T.T., Barate P., Frougier J., Vidal M., Renucci P., Xu B., Jaffres H., George J.-M., Devaux X., Hehn M., Marie X., Mangin S., Yang H.X., Hallal A., Chshiev M., Amand T., Liu H.F., Liu D.P., Han X.F., Wang Z.G., Lu Y. // Phys. Rev. B. 2014. V. 90. P. 085310.

[2] Holub M., Bhattacharya P. // J. Phys. D: Appl. Phys. 2007. V. 40. P. R179-R203.

[3] Zutic I., Fabian J., Das Sarma S. // Rev. Mod. Phys. 2004. V. 76. P. 323-410.

[4] Chen L., Yang X., Yang F., Zhao J., Misuraca J., Xiong P., von Molnár S. // Nano Lett. 2011. V. 11. P. 2584-2589.

[5] Kudrin A.V., Danilov Yu.A., Lesnikov V.P., Dorokhin M.V., Vikhrova O.V., Pavlov D.A., Usov Yu.V., Antonov I.N., Kriukov R.N., Alaferdov A.V., Sobolev N.A. // J. Appl. Phys. 2017. V. 122. P. 183901.

[6] Tu N.T., Hai P.N., Anh L.D., Tanaka M. // Appl. Phys. Express. 2018. V. 11. P. 063005.

[7] Ведь М.В., Дорохин М.В., Лесников В.П., Павлов Д.А., Усов Ю.В., Кудрин А.В., Дёмина П.Б., Здоровейщев А.В., Данилов Ю.А. // Письма в ЖТФ. 2019. Т. 45. В. 13. С. 3336.

[8] Ved M.V., Dorokhin M.V., Lesnikov V.P., Zdoroveyshchev A.V., Danilov Yu.A., Demina P.B., Kudrin A.V. // J. Phys.: Conf. Ser. 2019. V. 1410. P. 012053.

[9] Kudrin A.V., Lesnikov V.P., Danilov Yu.A., Dorokhin M.V., Vikhrova O.V., Pavlov D.A., Usov Yu.V., Antonov I.N., Kriukov R.N., Zubkov S.Yu., Nikolichev D.E., Konakov A.A., Dudin Yu.A., Kuznetsov Yu.M., Temiryazeva M.P., Sobolev N.A. // J. Magn. Magn. Mater. 2019. V. 485. P. 236243.

[10] Wimbauer Th., Oettinger K., Efros Al.L., Meyer B.K., Brugger H. // Phys. Rev. B. 1994. V. 50. P. 8889-8892. 